\section{Tidal Forces and the Formation of Hurricanes}

MaY I raise the following question: "Do tidal forces affect the formation of hurricanes ?" If one examines the changing direction of the tidal force due to the sun and a moon near new (or full) on an August day, say, as this force acts on a small element of air located at a point south of the subsolar latitude and north of the equator, one finds the tidal force would tend to make the atmospheric element move in a counter-clockwise direction as viewed from above. Furthermore, as the sun moves southward in August and early September, the latitudes where the highest atmospheric tides would be expected (here considered semi-diurnal), would fall alternately north and south of the equator, the successive points on either side approaching the equator. Might there not be one time at which the separation of these two latitudes would correspond to a natural frequency of oscillation of the atmosphere? If these arguments have any validity, the hurricanes in the North Atlantic should show an increase in number shortly before September 23 and a decrease shortly after that date.

The first date given for each tropical storm in the years 1900-49 inclusive was taken from Tannehill's "Hurricanes" (eighth revised edition, Princeton University Press, 1952) and the frequencies noted for a number of intervals in the hurricane season. The results are shown in Table 1.

Table 1

\begin{tabular}{|c|c|c|}
\hline Interval & Number & Number per week \\
\hline $\begin{array}{lc}\text { August } & 24-31 \\
\text { September } & 1-7 \\
\text { September } & 8-14 \\
\text { September } & 15-22 \\
\text { September } & 23-30 \\
\text { October } & 1-7 \\
\text { October } & 8-14\end{array}$ & $\begin{array}{l}32 \\
27 \\
40 \\
32 \\
20 \\
27 \\
26\end{array}$ & $\begin{array}{l}28 \\
27 \\
40 \\
28 \\
17 \cdot 5 \\
27 \\
26\end{array}$ \\
\hline
\end{tabular}

To determine whether the change from 40 for September 8-14 to $17 \cdot 5$ (per week) for September 23-30 was statistically significant, the fifty-year period was broken into five ten-year blocks and averages and variances determined. It was found that the change corresponded to $a 2$ per cent level of significance, that is, that this might happen by chance once in fifty times.

Also, if tidal forces play an important part in the formation of hurricanes, they should leave their mark on year-by-year statistics. Here I elected to break up the eighteen-year interval into four periods of four, five, four and five years. Then the number of hurricanes in each four-year period was increased by 25 per cent so that the comparison might be made on a uniform five-year basis. The results, again based on Tannehill, are shown in Table 2 .

\begin{tabular}{|c|c|c|}
\multicolumn{2}{c}{ Table 2 } & \\
\hline Interval & Number & Number per 5 years \\
\hline $1902-1905$ & 24 & 30 \\
$1906-1910$ & 35 & 35 \\
$1911-1914$ & 16 & 20 \\
$1915-1919$ & 28 & 28 \\
$1920-1923$ & 19 & $23 \cdot 8$ \\
$1924-1928$ & 34 & 34 \\
$1929-1932$ & 22 & $61 \cdot 5$ \\
$1933-1937$ & 61 & $33 \cdot 8$ \\
$1938-1941$ & 27 & 44 \\
\hline $1942-1946$ & 44 & \\
\hline
\end{tabular}

The average (on a five-year basis) for the four-year intervals was $27 \cdot 2(\sigma=4 \cdot 8)$. For the five-year intervals, the average was $40 \cdot 4(\sigma=11 \cdot 5)$.

I am aware that the tidal forces are not large; but $I$ would suggest that in meteorology the result is not always proportional to the force that triggers the action. I suggest that an investigation of atmospheric tides and their effects on the formation of hurricanes would be worth while.

\section{Charles H. Sminey}

Department of Astronomy,

Brown University்,

Providence 12, R.I. Nov. 2.

\section{Irradiation of Transistors}

THE effect of stored holes in transistors has been reported by Meacham and Michaels ${ }^{1}$, and the importance of the effect in the design of switching circuits was stressed by speakers in the discussion following a paper by Williams and Chaplin2. Briefly, good circuit design often necessitates operating a transistor in the condition where the collector current is limited by an external resistance; in this condition the time of fall of collector current upon cessation of emitter current is found to be much slower than when the collector current is limited only by the current gain of the transistor. It is the time of fall of collector current which determines the maximum switching speed of a transistor.

During some irradiation experiments on commercial point-type transistors in the Harwell pile, we have found that if a transistor is given a radiation dose of about $10^{14}$ neutrons/sq. cm., the time of fall of collector current from the value limited as described above is decreased, with little or no deterioration of the other parameters of the transistor. Curves of collector current against time after the sudden cessation of an emitter current of $3 \mathrm{~m}$.amp. are shown in Fig. 1 for the same transistor before irradiation and $2 \mathrm{hr}$. afterwards. The transistor used had a current gain of $2 \cdot 2$, so that at least $6 \cdot 6$ m.amp. of collector current was available; the collector current was limited to about 5.4 m.amp. by an external resistance.

Measurements have been repeated at intervals over a period of four weeks from the time of irradiation and have shown little change. Measurements after

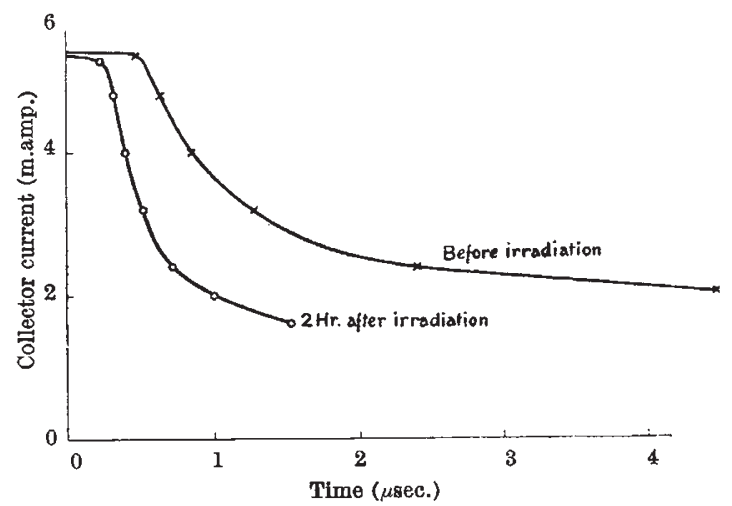

Fig. 1. Fall of collector current following cessation of emitter 